Geopolítica(s) Revista de estudios sobre espacio y poder ISSN: 2172-3958

https://dx.doi.org/10.5209/geop.69120

\title{
COVID-19: ¿(in)seguridad sin (in)movilidad? Acercando la política de la movilidad a los Estudios Críticos de Seguridad
}

\author{
Ángela Iranzo ${ }^{1}$
}

Recibido: 30 de abril de 2020 / Aceptado: 10 de mayo de 2020

Resumen. El artículo reflexiona sobre tres ideas: la pandemia de COVID-19, la seguridad y la movilidad. Si bien la potencial amenaza del coronavirus depende del movimiento (propagación, transmisión, infección), el movimiento y la movilidad son un "punto ciego" en los Estudios Críticos de Seguridad. El artículo propone analizar el nexo pandemia-seguridad a través de la lente de la política de la movilidad y explorar las ventajas analíticas de acercar el Paradigma de las Nuevas Movilidades a los Estudios Críticos de Seguridad. Argumenta que esta lente puede ayudar a explicar cómo intersectan y coproducen mutuamente las (in)movilidades e (in)seguridades asociadas a la pandemia. Además, al abordar el nexo pandemia-seguridad como parte de la política de la movilidad, emergen desafíos relevantes para los enfoques críticos de seguridad como explicar la dimensión discursiva en relación a otras como el movimiento y la experiencia; la acción de agencias humanas y no humanas; y las diferentes localizaciones del poder en sentido "multi-lugar".

Palabras clave: pandemia de COVID-19; seguridad; movilidad; política; Estudios Críticos de Seguridad.

\section{[en] COVID-19: (In)Security without (Im)Mobility? Bringing the Politics of Mobility to Critical Security Studies}

\begin{abstract}
The article is focused on three ideas: the COVID-19 pandemic, security and mobility. While the coronavirus is a potential security threat due to its movement (transmission, infection), both movement and mobility are a "blind spot" in Critical Security Studies. The purpose of this article is to analyse the pandemic-security nexus through the lens of the politics of mobility and explore the analytical benefits of bringing the Paradigm of the New Mobilities closer to Critical Security Studies. The article argues that this lens can help explain how (in)mobilities and (in)securities intersect and co-produce with each other. Moreover, in addressing the pandemic-security nexus within the politics of mobility, relevant challenges arise for Critical Security Studies such as explaining the discursive dimension in relation to others such as movement and experience; the action of human and nonhuman agencies; and the different locations of power as "multi-sited".
\end{abstract}

Keywords: COVID-19 pandemic; security; mobility; politics; Critical Security Studies.

1 Doctora en Ciencia Política y Relaciones Internacionales, Universidad Autónoma de Madrid.

E-mail: angela.iranzo@uam.es 


\title{
[pt] COVID-19: (in)segurança sem (in)mobilidade? Aproximando a política de mobilidade a os Estudos Críticos de Segurança
}

\begin{abstract}
Resumo. O artigo reflete sobre três ideias: a pandemia de COVID-19, segurança e mobilidade. Embora a ameaça potencial do coronavírus dependa de movimento (disseminação, transmissão, infeção), movimento e mobilidade são um "ponto cego" nos Estudos Críticos de Segurança. O artigo propõe analisar o nexo entre pandemia e segurança através das lentes da política de mobilidade e explorar as vantagens analíticas de aproximar o Novo Paradigma da Mobilidade dos Estudos Críticos de Segurança. Argumenta-se que essa lente pode ajudar a explicar como as (i)mobilidades e as (in)seguranças associadas à pandemia se interpenetram e se coproduzem. Além disso, ao abordar o nexo de pandemia e segurança como parte da política de mobilidade, emergem desafios relevantes para problemas críticos de segurança, como explicar a dimensão discursiva em relação a outras, como o movimento e a experiência; a ação de agências humanas e não humanas; e as diferentes localizações do poder em um sentido "multi-lugar".
\end{abstract}

Palavras-chave: pandemia da COVID-19; segurança; mobilidade; política; Estudos Críticos de Segurança.

Sumario. Introducción. 1. Movilidad. 2. Movilidad y seguridad. Conclusión. Referencias.

Cómo citar: Iranzo, A. (2020). COVID-19: ¿(in)seguridad sin (in)movilidad? Acercando la política de la movilidad a los Estudios Críticos de Seguridad. Geopolítica(s). Revista de estudios sobre espacio y poder, 11(Especial), 61-68.

\section{Introducción}

El artículo propone una reflexión en torno a tres ideas: la pandemia de COVID-19, la seguridad y la movilidad. Si partimos de la "necesidad" de enmarcar la COVID19 en la agenda de seguridad, de interpretarla como una amenaza de seguridad nacional y/o humana (Elbe, 2010), es posible identificar una controversia que, como dice Latour (2005), servirá al propósito de justificar la relevancia científica y política de la reflexión misma.

Un virus, en tanto origen de una enfermedad, se convierte en amenaza a través de una acción de movimiento; esto es, cuando se transmite o propaga, cuando entra en circulación e infecta. El virus deviene en epidemia (nacional) o pandemia (internacional) cuando tiene capacidad de moverse o circular. En el caso del coronavirus SARS-CoV-2, que produce la COVID-19, el movimiento subyace a su potencial naturaleza de amenaza desde el "salto", primero, de animales a humanos y, después, de humano a humano, pasando por intermediarios como tejidos y otras superficies materiales.

Sin embargo, si bien el movimiento pareciera ser una condición ontológica necesaria, aunque no suficiente, del alcance securitario de la pandemia, los Estudios Críticos de Seguridad no han incorporado la movilidad en sus análisis como fuerza constitutiva de lo político (Aradau, 2016; Leese y Wittendorp, 2017; Suliman, 2018). "Across this literature, the notion of mobility has always been central yet not necessarily discussed as such" (Guitet, 2017, p.210).

Ideas como movimiento y circulación, tomada ésta principalmente de los trabajos de Foucault (2008 y 2009), son frecuentes en sus investigaciones. Sin embargo, la mayoría de estos enfoques críticos se aproximan a las ideas de movimiento y 
movilidad como un rasgo de la epidemia o pandemia, una cualidad cuya capacidad explicativa es derivada; esto es, efecto de otros dispositivos de poder (conocimiento, discursos, prácticas sociales y tecnologías de gobierno) en torno a un tema: la producción de (in)seguridad. De este modo, la COVID-19 se presenta como un potente indicador sobre la subteorización política de la movilidad en los estudios de seguridad.

Por tanto, el propósito de este artículo es explorar las ventajas explicativas de acercar la política de la movilidad (Creswell, 2010; Suliman, 2016; 2018), desarrollada en el marco del Paradigma de las Nuevas Movilidades (Urry, 2000; Sheller y Urry, 2006), al análisis de la pandemia en los Estudios Críticos de Seguridad. Propone aproximarse a la movilidad y la seguridad como prácticas, producto y productoras de política, que modulan significativamente el alcance sociopolítico del coronavirus. Para ello, el artículo se detiene en la idea de política de la movilidad, formulada por el geógrafo Tim Creswell (2010), para explicar sus tres dimensiones (física, social y experiencial), ejemplificarlas en el caso de la COVID-19 y analizar las posibles ventajas de atender a las intersecciones entre (in)movilidad e (in)seguridad. Una breve conclusión cierra el artículo.

\section{Movilidad}

Un virus no se mueve solo, sino a través de vehículos (cuerpos humanos y no humanos) que en sus interacciones ensamblan la vida social y política. De modo que, como se argumenta a continuación, puede ser pertinente mirar a la COVID-19 desde los lentes de la política de la movilidad (Creswell, 2010) o política cinética, como la define Samid Suliman (2016; 2018).

Siguiendo la propuesta de Tim Creswell (2010), es posible identificar en la política de la movilidad, al menos, tres dimensiones: física, social y experiencial. La primera se refiere al movimiento; esto es, el desplazamiento por la superficie de la Tierra. Esta dimensión se analiza, como han hecho habitualmente los Estudios de Transporte, en función de elementos como la velocidad, la distancia, el ritmo, la dirección y rutas. Así, esta dimensión ofrece una cartografía de la pandemia sobre (el artificio de) un mundo plano, al tiempo que mide elementos como la velocidad, ritmo y dirección de propagación del virus que son centrales para la construcción de la COVID-19 como amenaza de seguridad nacional y/o humana.

La segunda dimensión corresponde a los significados socialmente atribuidos al movimiento. Son los marcos discursivos que definen los límites de lo posible. El coronavirus SARS-CoV-2 ha sido mayoritariamente interpretado en el mundo como una amenaza de seguridad; primero y esencialmente, a la vida humana pero también al sistema económico y el orden político de las democracias liberales. Diferentes gobiernos y medios de comunicación han definido y explicado la situación de crisis, provocada por la COVID-19, mediante el lenguaje bélico. El coronavirus es el "enemigo", el personal sanitario el "ejército" y las medidas políticas adoptadas han sido interpretadas como las propias de una "economía de guerra".

Este proceso de significación que una parte de los enfoques críticos de seguridad explica como securitización (Wæver, 1995), ha sido mayoritario hasta la fecha, aunque otras codificaciones de la pandemia son igualmente posibles (ej. desafío sanitario, medioambiental o cultural). 
Será necesario esperar un tiempo para conocer qué carreteras discursivas conducen el significado sociopolítico del virus y lo estabilizan como "lo normal". No obstante, esta segunda dimensión de la política de la movilidad podría abrir una salida a una de las críticas formuladas a la Teoría de la Securitización y otros enfoques críticos de seguridad: el riesgo de reducir el sentido político de $\mathrm{X}$-en este caso, la pandemia-, a un problema de seguridad y, con ello, reforzar la securitización que se busca evitar (Huysmans, 2006; Huysmans y Squire, 2009). La política de la movilidad, como herramienta heurística, está abierta a considerar y articular diferentes discursos (codificaciones sociales) como fuerzas constitutivas de las movilidades e inmovilidades. En definitiva, tiene la ventaja de explicar la producción de (in)seguridades en torno a la (in)movilidad de la pandemia, pero sin atraparla en el mundo (discursivo) de la seguridad.

Finalmente, la tercera dimensión apunta a la movilidad experimentada o vivida. Abre la cuestión de quién/qué se mueve y qué efectos políticos (ej. identificación, dominación, exclusión) tiene dicha movilidad como efecto $\mathrm{y}$, a su vez, como fuerza constitutiva -principalmente, en términos de agencia en tanto capacidad de acción. Es fácil trasladar esta dimensión a los cuerpos biológicos humanos como portadores del virus (infectados), con síntomas o asintomáticos, enfermos, fallecidos, personas o grupos poblacionales obligadas a guardar cuarentena o medidas como el confinamiento, la medición de la temperatura corporal u otros indicadores biopolíticos de salud. Sin embargo, esta dimensión, aplicada a la COVID-19, plantea otros retos. El objeto de protección/cuidado o el sujeto político susceptible de atención no sólo es el humano sino también el no humano. Audra Mitchell (2014) lo explica de la siguiente manera:

But security threats do not affect humans in isolation. Rather, they irrupt within the heterogeneous collectives that humans co-constitute with diverse nonhuman beings. War, for instance, destroys human lives and habitations, but also animal and plant life, landscapes and cultures, as well as the complex linkages between these phenomena (...) The enormity of these threats lies in the fact that they threaten not only certain beings, but rather whole worlds - that is, irreducible, heterogeneous forms of collective being. (p.5).

La reflexión de Mitchell muestra la posibilidad de incluir en la agenda de seguridad los diversos relacionamientos entre las experiencias vitales de los humanos y de los no humanos. La COVID-19, y la política de la movilidad que subyace a su gestión, ha puesto de manifiesto una dislocación importante: el aumento de la seguridad (pulsión de vida) del hábitat natural, a medida que crece la amenaza epidemiológica sobre la vida de los humanos y sus hábitats sociales. De este modo, la lectura crítica no se agota al trasladar el "referente de seguridad" del Estado al individuo, o incluso a la naturaleza como otra esfera o componente de la realidad a proteger (la lectura moderna de diferenciación de las esferas de la vida). Más bien, como sostienen voces feministas y de-coloniales, consiste en aproximarse a los problemas de seguridad como daños sobre mundos o cosmologías ("wordly security"), que cobran existencia relacionalmente más que en un sentido agregado ${ }^{2}$.

2 Sobre el concepto de relacionalidad en Relaciones Internacionales, véase Milja Kurki (2000). 
Estas tres dimensiones, cada una en sus infinitas posibles formas, se integran entre sí y conforman lo que Creswell (2010) denomina "constelaciones de movilidad". Esto es, la política de la movilidad ha de ser estudiada en sus contextos espacio-temporales: "[It is] as a way of accounting for historical senses of movement that is attentive to movement, represented meaning, and practice and the ways in which these are interrelated" (Creswell, 2010, p.26).

\section{Movilidad y seguridad}

Si el coronavirus es una amenaza en función de su movilidad, prestar atención a las intersecciones entre movilidad e inmovilidad será útil para comprender sus modulaciones en clave de (in)seguridad. A tal fin, son necesarias, al menos, dos aclaraciones.

Primero, la movilidad e inmovilidad del virus (corporeizado en humano, animal u objeto material) no son acciones opuestas. Más allá del enfoque binario y posibles asociaciones normativas estables (ej. el movimiento es peligroso o el confinamiento es protección), la movilidad es un concepto relacional para el "mobility turn" (Adey, 2006; Hannan, Sheller y Urry, 2006). La una es el afuera constitutivo de la otra. En otras palabras, la movilidad es un componente de la inmovilidad y viceversa. La condición de estar en movimiento produce fricciones, frenos o entrampamientos (ej. confinamiento, cuarentena, controles de paso, detención); y, del mismo modo, el movimiento se origina a partir de una condición estática (ej. aumento de la movilidad social mediante las tecnologías en estado de inmovilidad física, o la movilidad permitida mediante medidas de des-confinamiento). De este modo, al igual que los enfoques críticos se distancian de los binarios para abordar la idea de seguridad-inseguridad, el Paradigma de las Nuevas Movilidades se aproxima al concepto de movilidad.

Segundo, si el ejercicio consiste entonces en comprender cómo las (in)movilidades del virus interactúan con la producción de (in)seguridades, el lugar epistemológicamente valioso para ello es la intersección. Se abre aquí una perspectiva que desestabiliza la onto-epistemología sedentarista presente en un sector importante de los enfoques críticos de seguridad en Relaciones Internacionales (Suliman, 2018) ${ }^{3}$. La pregunta por "el lugar" de la co-producción y "el lugar" de la investigación (dónde situar la mirada analítica), implica re-pensar la política de la movilidad (las tres dimensiones propuestas por Creswell) a la luz de sus localizaciones (en tanto espacios de intersección).

En este sentido, sería posible sostener que la dimensión física de la movilidad se localiza en el espacio geográfico (lugares concretos no necesariamente circunscritos al territorio del Estado o más allá de la ficción de los niveles de análisis localnacional-regional-internacional-global); la dimensión discursiva en instituciones (cuando los significados atribuidos adquieren altos niveles de aceptación) que no actúan unas sobre otras bajo una metafísica vertical (internacionales sobre naciona-

3 Si bien estos enfoques defienden una ontología del mundo político internacional originada en las prácticas sociales, siguen mayoritariamente anclados a una metodología estática o sedentarista al explicar la producción del poder y la autoridad. Véase, por ejemplo, Hynek y Chandler (2013), Browning y McDonald (2013). 
les u otros) sino a través de conectores (prácticas de ensamblado); y finalmente, la dimensión experiencial se localiza en los cuerpos (biológicos o materiales).

A su vez, estas tres localizaciones son interpretadas como prácticas "multilugar" ("multi-sited"); esto es, los lugares particular (localización o territorialización geográfica) dentro de un entramado social complejo, pueden ser entendidos como un lugar múltiple (donde cristalizan de forma particular muchos lugares, tiempos, actores y significados), al mismo tiempo que múltiples localizaciones o lugares pueden ser interpretados como un único lugar geográfico discontinuo porque comparten lógicas de articulación (Elliot, Norum y Salazar, 2017).

Tabla 1. La política de la movilidad: herramienta analítica

\begin{tabular}{|c|c|c|c|}
\hline \multirow{2}{*}{$\begin{array}{c}\text { Dimensiones de } \\
\text { la movilidad }\end{array}$} & \multirow{2}{*}{$\begin{array}{l}\text { Elementos constitutivos } \\
\text { (mundos de la acción) }\end{array}$} & \multicolumn{2}{|c|}{ Localizaciones } \\
\hline & & Paisajes I & Paisajes II \\
\hline Movimiento & $\begin{array}{cl}\text { Elementos físicos } \\
\text { - } & \text { Distancia } \\
\text { - } & \text { Velocidad } \\
\text { - } & \text { Ritmo } \\
\text { - } & \text { Sentido } \\
\text { - } & \text { Rutas } \\
\end{array}$ & Geográfico & \multirow{3}{*}{ Multi-lugar } \\
\hline $\begin{array}{l}\text { Movilidad } \\
\text { significada }\end{array}$ & $\begin{array}{cl}\text { Discursos dominantes } \\
\text { - } & \text { Seguridad } \\
\text { - } & \text { Salud } \\
\text { - } & \text { Medioambiente } \\
\text { - } & \text { Cosmología }\end{array}$ & Institucional & \\
\hline $\begin{array}{l}\text { Movilidad } \\
\text { experimentada }\end{array}$ & $\begin{array}{l}\text { Vivencias cotidianas } \\
\text { - Agencia } \\
\text { - Objeto }\end{array}$ & Corporal & \\
\hline
\end{tabular}

Fuente: Tabla de confección propia, adaptación de una herramienta metodológica diseñada para un proyecto de investigación sobre intersecciones seguridad-movilidad de migrantes "en tránsito".

En definitiva, acercar el "mobility turn" a los Estudios Críticos de Seguridad se traduce en analizar el nexo movilidad-seguridad en relación a la COVID-19 desde la intersección, entendida ésta como un lugar inestable, discontinuo y multi-lugar. En definitiva, un lugar en continua vibración o movimiento (Latour, 2005; Collier y Ong, 2005; Law, 2007) que, sin embargo, difiere del sentido abstracto y desterritorializado de ideas como "flujo" o "liquidez" (Bauman, 2000).

\section{Conclusión}

El artículo llama la atención sobre el movimiento; una dimensión que, como dijo la geógrafa Doreen Massey (2012), está inexorablemente unida a todo análisis crítico del espacio. Si el espacio está socialmente construido a través de la interacción, es espacio-tiempo y, por tanto, movimiento.

En particular, argumenta que un virus es un agente biológico que impacta en la dimensión sociopolítica a través del movimiento. Por lo tanto, los debates que enmarcan el coronavirus SARS-CoV-2 en la agenda de seguridad, deberían atender a 
las intersecciones entre movilidad e inmovilidad del virus como nodos constitutivos de sus efectos de (in)seguridad — sea estatal, individual, de grupos sociales, medioambiental o cosmológica-.

Sin embargo, aunque el movimiento es una condición necesaria para que el virus se convierta en amenaza (propagación, transmisión, contagio), los Estudios Críticos de Seguridad han prestado escasa atención a éste como fuerza constitutiva de lo político. Esto revela la metafísica sedentarista que subyace a este campo de conocimiento y, en general, a su disciplina matriz, las Relaciones Internacionales, que han superado en gran medida el estadocentrismo pero no el sedentarismo.

Los enfoques críticos de seguridad han incorporado en sus explicaciones muchos de los "giros" de las Ciencias Sociales (epistemológico, crítico, social, lingüístico, cultural, entre otros). Han abrazado también el "giro espacial" readaptando el uso de herramientas conceptuales propias de la Geografía como "espacio", "lugar" o "escala". Sin embargo, apenas se han detenido en los aportes del "giro de la movilidad" ("mobility turn"). Así, el artículo ha mostrado algunas de las posibles ventajas analíticas de analizar el nexo pandemia-seguridad desde las lentes de la política de la movilidad, desarrollada por el Paradigma de las Nuevas Movilidades.

Esta lente puede ayudar a abrir el camino a una agenda de investigación que analice cómo intersectan y se producen mutuamente las (in)movilidades e (in)seguridades asociadas a la pandemia. Cómo operan estas intersecciones, qué ensamblajes de fuerzas las constituye, qué diferentes efectos de poder producen o dónde se localizan, son solo algunas de las preguntas pendientes. Será necesario trabajar en la confección rigurosa de esta agenda. No obstante, al abordar el nexo coronavirus-seguridad desde la política de la movilidad, surgen desafíos importantes para muchos de los enfoques críticos de seguridad. Algunos de ellos son atender a la dimensión discursiva entramada en otras como el movimiento y la experiencia, la acción de agencias humanas y no humanas (biológicas y materiales), así como las localizaciones del poder en un sentido "multi-lugar".

En conclusión, el artículo sostiene una idea sencilla: las (in)seguridades asociadas a la pandemia de COVID-19 están insertas en la política de la (in)movilidad. Por tanto, ¿por qué no reconocer el valor explicativo y político de la movilidad?

\section{Referencias}

Adey, P. (2006). If Mobility is Everything then it is Nothing: Towards a Relational Politics of (Im)mobilities. Mobilities, 1(1), 75-94.

Aradau, C. (2016). Political Grammars of mobility, security and subjectivity. Mobilities, 11(4), 564-574.

Bauman, Z. (2000). Liquid Modernity. Cambridge: Polity Press.

Browning, C. S., y McDonald, M. (2013). The Future of Critical Security Studies: Ethics and the Politics of Security. European Journal of International Relations, 19(2), 235255.

Collier, S., y Ong, A. (Eds.). (2005). Global Assemblages: Technology, Politics and Ethics as Anthropological Problems. Malden, MA: Blackwell.

Creswell, T. (2010). Towards a politics of mobility. Environment and planning D: Society and Space, 28(1), 17-31. 
Elbe, S. (2010). Pandemic Security. En P. Burgess. (Ed.), The Routledge Handbook of New Security Studies (pp.163-172). Londres, Inglaterra y Nueva York, Estados Unidos: Routledge.

Elliot, A., Norum, R., y Salazar, N. B. (Eds.). (2017). Methodologies of Mobility. Nueva York, Estados Unidos: Berghahn Books.

Foucault, M. (2009). El nacimiento de la biopolitica. Cursos del Collège de France (197879). Madrid, España: Akal.

Foucault, M. (2008). Seguridad, territorio y población. Cursos del Collège de France (1977-78). Madrid, España: Akal.

Guitet, E. (2017). Unpacking the new mobilities paradigm: Lessons for Critical Security Studies? En M. Lesse y S. Wittendorp. (Eds.), Security/Mobility. Politics of movement (pp.209-216). Manchester, Inglaterra: Manchester University Press.

Hannan, K., Sheller, M., y Urry, J. (2006). Editorial: Mobilities, Immobility and Moorings. Mobilities, 1(1), 1-22.

Huysmans J., y Squire, V. (2009). Migration and security. En M. D. Cavelty y T. Bazacq. (Eds.), Handbook of Security Studies (pp.161-171). Londres, Inglaterra: Routledge.

Huysmans, J. (2006). The politics of insecurity. Fear, migration and asylum in the EU. Londres, Inglaterra y Nueva York, Estados Unidos: Routledge.

Hynek, N., y Chandler, D. (2013). No Emancipation Alternative, No Critical Security Studies. Critical Studies on Security, 1(1), 41-63.

Kurki, M. (2020). International Relations in a Relational Universe. Oxford, Inglaterra: Oxford University Press.

Latour, B. (2005). Reensamblar lo social. Buenos Aires, Argentina: Manantial.

Law, J. (2009). Actor Network Theory and Material Semiotics. En B. S. Turner. (Ed.), The New Blackwell Companion to Social Theory. Malden, MA; Oxford y West Sussex, Inglaterra: Blackwell Publishing.

Lesse, M., y Wittendorp, S. (Eds.). (2017). Security/Mobility. Politics of movement. Manchester, Inglaterra: Manchester University Press.

Massey, D. (2012). La filosofía y la política de la espacialidad. Algunas consideraciones. En A. Albet y N. Benach (Eds.), Doreen Massey: un sentido global del lugar (pp.156181). Barcelona, España: Icaria.

Mitchell, A. (2014). Only Human? A Worldly Approach to Security. Security Dialogue, 45(1), 5-21.

Sheller, M., y Urry, J. (2006). The new mobilities paradigm. Environment and Planning A, $38(2), 207-226$.

Suliman, S. (2018). Mobilising a theory of Kinetic Politics. Mobilities, 13(2), 276-290.

Suliman, S. (2016). Mobility and the Kinetic Politics of Migration and Development. Review of International Studies, 42(4), 702-23.

Urry, J. (2000). Mobilities for the Twenty-first Century. Londres, Inglaterra: Routledge.

Wæver, O. (1995). Securitization and desecuritization. En R. D. Lipschutz (Ed.), On Security (pp.46-87). Nueva York, Estados Unidos: Columbia University Press. 